\title{
Slope of the dose-response curve: usefulness in assessing bronchial responses to inhaled histamine
}

\author{
DW COCKCROFT, BA BERSCHEID
}

From the Section of Respiratory Medicine, University Hospital, University of Saskatchewan, Saskatoon, Canada

ABSTRACT The value of determining the slope of the histamine dose-response curve, in addition to the histamine provocation concentration producing a $20 \%$ reduction in $\mathrm{FEV}_{1}\left(\mathrm{PC}_{\left.20-\mathrm{FEV}_{1}\right) \text {, was }}\right.$ assessed by analysis of histamine dose-response curves in 40 patients selected as having a wide range of increased non-specific bronchial responsiveness to inhaled histamine. The histamine dose-response curves were found to fit the linear curve (dose $v$ response, mean $r^{2}=0.97$ ) better than the logarithmic curve (log dose $v$ response, mean $\left.\mathrm{r}^{2}=0.93\right)$, the difference being significant $(\mathrm{p}<0.001)$. There was a strong negative correlation between the $\mathrm{PC}_{20-\mathrm{FEV}}$ and the slope $(\mathrm{r}=$ $-0.98, \mathrm{p} \ll 0.001)$ and a weak negative correlation between the $\mathrm{PC}_{20-\mathrm{FEV}}$ and the log-doseresponse slope $(r=-0.38, p<0.05)$. Sixteen normal subjects and 16 asthmatic patients were compared on the basis of histamine dose-response curves measuring fall in sGaw. In this study there was no difference between $\mathrm{r}^{2}$ for the linear determination and for the logarithmic determination $(0.91 v 0.90, \mathrm{p}>0.05)$. The $\mathrm{PC}_{35 \text {-sGaw }}$ showed a strong negative correlation with the dose-response slope $(\mathrm{r}=-0.95, \mathrm{p} \ll 0.01)$ and no correlation with the log-dose-response slope $(\mathrm{r}$ $=0.09, \mathrm{p}>0.05)$. In the two studies there appeared to be little information gained from the determination of either the dose-response slope or the log-dose-response slope. The slope and the $\mathrm{PC}_{20-\mathrm{FEV}}$, were equally reproducible, duplicate determinations showing less than a two-fold difference in 14 of 15 paired $\mathrm{PC}_{20}$ measurements and in 13 of 15 paired slope measurements. In summary, the slope of the histamine dose-response curve appears to fit the linear model better than the logarithmic model. It is feasible to calculate it from the results of a standardised histamine inhalation test; determination of either the slope or the log-dose-response slope, however, appears to add little useful information. It is recommended that bronchial provocation test results should be expressed in terms of a threshold concentration such as the $\mathrm{PC}_{20-\mathrm{FEV}}$ or the $\mathrm{PC}_{35 \text {-sGaw. }}$.

Measurements of non-specific bronchial responsiveness to inhaled histamine or inhaled cholinergic agonists such as methacholine has become an important diagnostic and research aid. ${ }^{2}$ Inhalation tests are performed with increasing doses of the provoking agents, and the results are generally expressed either as the first dose or concentration which produces more than a predetermined response or as the interpolated dose producing a given response. For example, the histamine provocation concentration producing a $20 \%$ decline in the one-second forced expired volume $\left(\mathrm{FEV}_{1}\right)$ is referred to as the his-

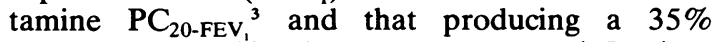
decrease in specific airway conductance (sGaw) as

Address for reprint requests: Dr DW Cockcroft, University Hospital, Saskatoon, Saskatchewan, Canada, S7N OXO. the histamine $\mathrm{PC}_{35 \text {-sGaw. }}{ }^{4}$ Recently, however, Orehek et al suggested that a more detailed examination of bronchial provocation dose-response curves was valuable. ${ }^{5}$ These authors made a distinction between the slope of the inhaled carbachol dose-response curve, referred to as "reactivity," and the dose causing a $25 \%$ reduction in sGaw ( $\left.\mathrm{PC}_{25 \text {-sGaw }}\right)$, referred to as "sensitivity." It was suggested that different mechanisms may determine "reactivity" and "sensitivity,", that "hyperreactivity" was more important to the asthmatic state than was "hypersensitivity," and that both should be determined when bronchial provocation tests are being interpreted.

We have developed a standardised, reproducible histamine inhalation test which has proved useful in extensive clinical research. ${ }^{36-9}$ Test results have 
been expressed as the histamine $\mathrm{PC}_{20-\mathrm{FEV}}$ or the

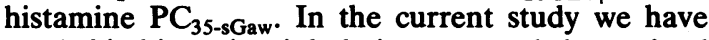
used this histamine inhalation test and determined the slope of the histamine dose-response curves. We have evaluated both the feasibility and the usefulness of measuring "reactivity" by this method. We have also assessed whether the histamine doseresponse slope fits the linear or the logarithmic curve better.

\section{Methods}

\section{Subjects}

Normal subjects with no history of asthma, rhinitis, or other respiratory disorder; subjects with asthma ${ }^{10}$; and subjects with rhinitis were selected from the respiratory diseases clinic at the University Hospital in Saskatoon and from volunteers within the laboratory. Those who were taking medications were asked to refrain from using antihistamines for 48 hours and bronchodilators for eight hours; corticosteroids were continued in the same dose. The subjects were non-smokers. This investigation was approved by the ethics committee of the University of Saskatchewan and signed informed consent was obtained.

\section{Histamine inhalation test}

The standardised histamine inhalation test was performed as previously outlined. ${ }^{37}$ After a control inhalation of normal saline, doubling concentrations of histamine acid phosphate from 0.03 to $8.0 \mathrm{mg} / \mathrm{ml}$ were inhaled for two minutes at five-minute intervals. Inhalations were made via a face mask from a Wright nebuliser operated with an airflow rate of 7 $1 / \mathrm{min}$ and with $5 \mathrm{ml}$ of solution in the vial. The output of the nebuliser was $0.130 \mathrm{ml} / \mathrm{min}$ and the particle size mass median diameter $1 \mu \mathrm{m}$.

The histamine $\mathbf{P C}_{20-\mathrm{FEV}}$ was determined by means of $\mathrm{FEV}_{1}$ measurements from a Godart 9-litre water spirometer. The FEV 1 was measured in triplicate before the inhalations and again 30 and 90 seconds after each inhalation. If the 90-second $\mathrm{FEV}_{1}$ was less than the 30-second FEV the measurement was repeated three and if necessary five minutes after the inhalation. The test was continued until FEV had fallen by $20 \%$ or more, or until the top concentration had been inhaled. The percentage reduction in FEV 1 was calculated from the lowest post-saline $F E V_{1}$ to the lowest post-histamine $\mathrm{FEV}_{1}$ for each histamine concentration. The histamine $\mathrm{PC}_{20-\mathrm{FEV}_{1}}$ was then calculated from the dose-response curve by linear interpolation between the last two points, as previously described. ${ }^{3}$

The histamine $\mathrm{PC}_{35-\mathrm{sGaw}}$ was determined (in sepa-

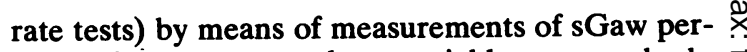
formed in a constant-volume variable-pressure body plethysmograph (Cardio-Pulmonary Instruments, Model 2000). The mean of four measurements of sGaw was calculated before the inhalations, and again 30-90 seconds after each inhalation. The percentage reduction in sGaw was calculated from the post-saline mean sGaw to the post-histamine mean sGaw at each histamine concentration. The test was $\vec{\circ}$ continued until there had been a $35 \%$ or greater reduction in sGaw, or until the top histamine $\vec{\omega}$ concentration had been administered. The histamine $\mathrm{PC}_{35 \text {-sGaw }}$ was determined from the last two points of the histamine dose-response curve in a $\omega_{\infty}$ manner similar to the histamine $\mathrm{PC}_{20-\mathrm{FEV}_{1}}$.

The slope of each histamine dose-response curve of was determined by means of the method of least- 0 squares linear regression. ${ }^{11}$ The first point showing a measurable reduction in either $\mathrm{FEV}_{1}$ or sGaw and $c$ all subsequent points were used in the regression. Both the slope of the linear curve (percentage reduction versus dose) and the slope of the $₹$ logarithmic curve (percentage reduction versus $\log \vec{\varphi}$ dose) were calculated. The coefficient of determina- $\omega$ tion $\left(r^{2}\right)$ was determined for each regression.

STUDY NO 1: $\mathrm{PC}_{20-\mathrm{FEV}}$

Forty subjects were selected to participate in the study. All were known to have increased bronchial $\bar{\varnothing}$ responsiveness to inhaled histamine with a histamine $\mathrm{PC}_{20-\mathrm{FEV}_{1}}$ of less than $8.0 \mathrm{mg} / \mathrm{ml}$. They included 30 with bronchial asthma, six with rhinitis, and four normal individuals with mildly increased responses to histamine. The subjects were selected to represent a wide range of bronchial responsive- $\vec{\partial}$ ness; their $\mathrm{PC}_{20} \mathrm{~S}$ ranged from 0.06 to $8.0 \mathrm{mg} / \mathrm{ml}$. The histamine $\mathrm{PC}_{20-\mathrm{FEV}_{1}}$ and both the dose-response ${ }_{0}^{x}$ slope and the log dose-response slope were calculated from each of the 40 curves. Determination of the slopes of the dose-response curves was based on two points in nine subjects, three points in 26 subjects and four points in five subjects.

Logarithmic transformation of $\mathrm{PC}_{20}$ and of slope $\frac{D}{0}$ of the dose-response curve, but not the slope of the log dose-response curve, was required for the $N$ analysis. Firstly, the coefficients of determination $N$ $\left(r^{2}\right)$ of the slope of the linear dose-response curve $N$ and of the slopes of the log dose-response curve ${ }^{\omega}$ (from the 31 curves with more than two points) were compared by means of the paired $t$ test. ${ }^{12}$ Secondly, correlation between the $\mathrm{PC}_{20-\mathrm{FEV}}$ and the slopes of both the linear and the log dose-response curves was sought by the method of least-squares linear regression. ${ }^{11}$ Finally, the 20 subjects with the highest and $\underset{\mathbb{D}}{ }$

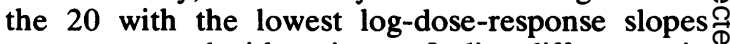
were compared with a view to finding differences in 2 
clinical features; Student's $t$ test $^{13}$ and the $\chi^{2}$ test $^{14}$ were used.

STUDY NO 2: PC $_{35-s G a w}$

The second study was carried out to compare asthmatic with normal subjects. Sixteen patients with well-documented asthma ${ }^{10}$ and 16 normal subjects participated. All had a $30 \%$ or greater reduction in sGaw after inhalation of the top concentration (8 $\mathrm{mg} / \mathrm{ml}$ ) of histamine-that is, the $\mathrm{PC}_{35-\mathrm{sGaw}}$ was less than $10 \mathrm{mg} / \mathrm{ml}$. We had to test 36 normal subjects to find 16 with a $30 \%$ reduction in sGaw after $8 \mathrm{mg} / \mathrm{ml}$ of histamine. Histamine dose-response curves were obtained and the PC $_{35 \text {-sGaw }}$ was determined as well as the slopes of the dose-response curve and the log-dose-response curve. Determination of the slopes was based on two points in two subjects, three points in 19 subjects, four points in 10 subjects, and five points in one subject.

The analysis was performed in the same way as in the first study. The coefficients of determination for the linear and log slopes were compared for the $\mathbf{3 0}$ curves where more than two points were used in the regression. The $\mathbf{P C}_{35-\mathrm{sGaw}}$ was regressed with the slopes of both the linear and the log-dose-response curves. In addition, the asthmatic were compared with the normal subjects with regard to anthropometric data, baseline $\mathrm{sGaw}, \mathrm{PC}_{35-\mathrm{sGaw}}$, slope of dose-response curve, and slope of log-doseresponse curve by means of Student's $t$ test. ${ }^{13}$

\section{STUDY NO 3: REPRODUCIBILITY}

The reproducibility of measurements of $\mathrm{PC}_{20-\mathrm{FEV}}$ and the slope of the curve was assessed by duplicate histamine inhalation tests. The tests were performed at the same time of day within one week; baseline FEV varied by less than $10 \%$ and there was no history of recent respiratory infection or allergen exposure. Fifteen asthmatic subjects whose $\mathbf{P C}_{20}$ was less than $8 \mathrm{mg} / \mathrm{ml}$ participated in this study. From the two tests the percentage difference between the two determinations of $\mathrm{PC}_{20}$ and of the slope of the curve was calculated by the formula

$$
\frac{\text { difference in } 2 \text { tests' results }}{\text { mean value of } 2 \text { tests' results }} \times 100 \text {. }
$$

The results were compared by means of the paired $t$ test. $^{12}$

\section{Results}

STUDY NO 1: PC $_{20-F E V}$,

Details of the $\mathbf{4 0}$ subjects in this study are given in table 1. The slope of the histamine dose-response curve fitted the linear model better than the logarithmic model; the mean $\mathbf{r}^{2}$ for the percentage fall versus dose regressions was $0.97 \pm 0.03$ and for the percentage fall versus log-dose-regressions 0.93 \pm 0.06 (difference significant, $p<0.001$ ). The histamine $\mathrm{PC}_{20}$ is compared with the slope of the dose-response curve in figure 1 . There was a more than 100 -fold range in $\mathrm{PC}_{20}$ values, from 0.06 to 8.0 $\mathrm{mg} / \mathrm{ml}$; and there was a similar range in slopes, values ranging from 3 to $460(\% \mathrm{fall} / \mathrm{mg} / \mathrm{ml})$. There was a strong negative correlation between the $\mathrm{PC}_{20}$ and the slope $(r=-0.98, p \ll 0.001)$, the slope of the curve being larger in subjects with a low $\mathrm{PC}_{20}$. Only one subject fell outside the $95 \%$ confidence of limits of this regression (fig 1). The histamine $\mathbf{P C}_{20}$ was then compared with the slope of the log-doseresponse curve (fig 2 ). The range of the values for this slope was smaller, from 12 to 90 (\% fall/log $\mathrm{mg} / \mathrm{ml})$. There was a weak negative correlation between the $\mathrm{PC}_{20}$ and the log-dose-response slope $(\mathrm{r}=$ $-0.38, p<0.05)$. In an effort to determine whether there was any significance in the differences

Table 1 Comparison of subjects with high and low log-dose-response curves

\begin{tabular}{|c|c|c|c|}
\hline & 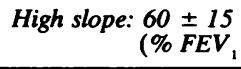 & $\begin{array}{l}\text { Low slope: } 27 \pm 6 \\
\mathrm{mg} / \mathrm{ml})\end{array}$ & Significance \\
\hline $\begin{array}{l}\text { Number of subjects } \\
\text { Number with asthma } \\
\text { Number with rhinitis } \\
\text { Number of normal subjects } \\
\text { Age (y) (mean } \pm \text { SD) } \\
\text { Sex (male: female) } \\
\text { Number with atopy } \\
\text { Duration of symptoms (y) } \\
\text { FEV, (l) } \\
\text { Histamine PC } 20-F E V_{\text {. }}\end{array}$ & $\begin{array}{l}20 \\
17 \\
2 \\
1 \\
38 \pm 18 \\
7: 13 \\
16 \\
11 \pm 11 \\
2.61 \pm 0.81 \\
0.79^{*}\end{array}$ & $\begin{array}{l}20 \\
13 \\
4 \\
3 \\
35 \pm 17 \\
11: 9 \\
7 \\
7.7 \pm 9.5 \\
2.98 \pm 0.84 \\
1.97^{*}\end{array}$ & $\begin{array}{l}\text { NS } \\
\text { NS } \\
\text { NS } \\
\text { NS } \\
\text { NS } \\
\text { p< }<0.05 \\
\text { NS } \\
\text { NS } \\
\text { p }<0.05\end{array}$ \\
\hline $\begin{array}{l}\text { Asthma treatment: number having } \\
\text { none } \\
\text { adrenergic bronchodilators } \\
\text { theophylline } \\
\text { steroids }\end{array}$ & $\begin{array}{r}9 \\
10 \\
4 \\
8\end{array}$ & $\begin{array}{r}11 \\
9 \\
2 \\
5\end{array}$ & $\begin{array}{l}\text { NS } \\
\text { NS } \\
\text { NS } \\
\text { NS }\end{array}$ \\
\hline
\end{tabular}

*Geometric mean. 
observed in the slope of the histamine log-doseresponse curve, the 20 subjects with the highest log-dose-response slope (38-90) were compared with the 20 with the lowest values (12-37) (table 1). As was anticipated from the significant regression (fig 2), those with the higher slopes had a slightly lower $\mathrm{PC}_{20}(0.79 v 1.97, \mathrm{p}<0.05)$. There were no significant differences in anthropometric data, duration of symptoms, $\mathrm{FEV}_{1}$ or asthma treatment between the two groups; the only difference was a significantly greater prevalence of atopy $(16 v 7$, $p<0.05)$ in the group with the higher slope.

STUDY NO 2: PC $_{35 \text {-sGaw }}$

Details of the 32 subjects (16 asthmatic and 16 normal) are given in table 2 . The results of the second study are similar to those of the first. The linear model for the regressions was similar to the logarithmic model $\left(\mathrm{r}^{2}=0.91 \pm 0.1 v 0.90 \pm 0.1, \mathrm{p}\right.$ $>0.05$ ). The $\mathrm{PC}_{35}$ and the dose-response slope were compared (fig 3 ). There was a similar magnitude of ranges, with $\mathrm{PC}_{35}$ ranging from 0.04 to 10 and the slope from 2 to 400 . A strong negative correlation between $\mathrm{PC}_{35}$ and the dose-response slope $(\mathrm{r}=$ $-0.95, p \ll 0.001)$ is seen in fig 3 . There was no significant correlation between the $\mathrm{PC}_{35}$ and the log-dose-response slopes between the asthmatic and normal and asthmatic subjects were compared in table 2. The asthmatic subjects were somewhat older (46 $v 29$ years) and had more severe airflow obstruction, as shown by lower mean values for both $\mathrm{FEV}_{1}$ and sGaw. The significant differences between asthmatic and normal subjects in $\mathrm{PC}_{35}(0.33 v 4.8, \mathrm{p}$ $<0.001)$ and the dose-response slope $(75 v 7.6, \mathrm{p}<$ 0.001 ) were of the same order of magnitude (about 10 -fold). An important point is that the 16 normal subjects included in this study were selected from 36 normal subjects, and they represent those with the lowest $\mathrm{PC}_{35}$ values in the group. Consequently, the mean value for normal individuals in this study $\left(\mathrm{PC}_{35}=4.8\right)$ cannot be taken as representative of our normal subjects. There was no difference in the log-dose-response slopes between the asthmatic and normal subjects.

\section{STUDY NO 3: REPRODUCIBILITY}

The histamine $\mathrm{PC}_{20-\mathrm{FEV}_{1}}$ and the dose-response slope were equally reproducible. The $\mathbf{P C}_{20}$ was reproducible to within one doubling dilution in 14 of the 15 subjects; this is similar to our previous observation. ${ }^{7}$ There was no significant difference between the percentage differences in the two determinations of $\mathrm{PC}_{20}(23 \pm 23)$ and the slope $(34 \pm 26)(\mathrm{p}>$ $0.05)$.



Fig 1 Histamine $\mathrm{PC}_{20-\mathrm{FEV}}$ versus slope of the histamine dose-response curve. The $\mathrm{PC}_{20}(\mathrm{mg} / \mathrm{ml})$ is on the horizontal axis and the slope (\% FEV, fall/mg/ml) on the vertical axis. $A$ marked negative correlation $(r=-0.98, p \ll 0.001)$ is evident.

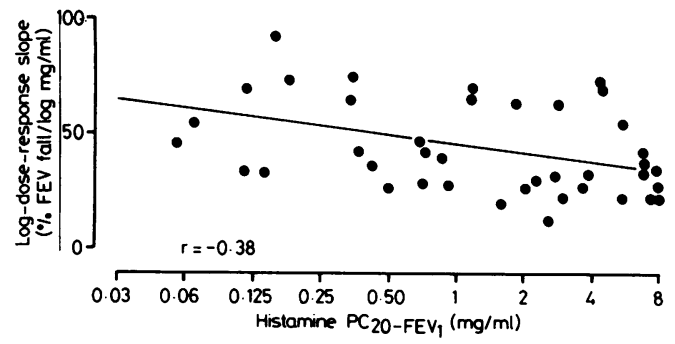

Fig 2 Histamine $\mathrm{PC}_{20-\mathrm{FEy}}$ versus slope of the histamine log-dose-response curve, showing a weak negative correlation $(r=-0.38, p<0.05)$

Table 2 "Reactivity" and "sensitivity" to inhaled histamine in normal and asthmatic subjects

\begin{tabular}{|c|c|c|c|}
\hline & Normal & Asthmatic & Significance \\
\hline $\begin{array}{l}\text { Number of subjects } \\
\text { Age (y) (mean } \pm \mathrm{SD}) \\
\text { Sex (male: female) } \\
\text { Height }(\mathrm{cm}) \\
\text { FEV }(\text { litres) } \\
\text { sGaw }\left(1 \mathrm{~s}-1 \mathrm{~cm} \mathrm{H}_{2} \mathrm{O}^{-1}\right. \\
\text { Histamine } \mathrm{PC}_{35-\mathrm{sGaw}}(\mathrm{mg} / \mathrm{ml}) \\
\text { Slope of dose-response curve }\left(\% \mathrm{FEV}_{1} \text { fall } / \mathrm{ml}\right) \\
\text { Slope of log-dose-response curve }\left(\% \mathrm{FEV}_{1} \text { fall/log } \mathrm{mg} / \mathrm{ml}\right)\end{array}$ & $\begin{array}{l}16 \\
29 \pm 10 \\
6: 10 \\
169 \pm 11 \\
3 \cdot 60 \pm 1 \cdot 0 \\
0 \cdot 23 \pm 0 \cdot 07 \\
4 \cdot 8 \pm 1 \cdot 7^{*} \\
75 \pm 4 \cdot 4^{*} \\
61 \pm 32\end{array}$ & $\begin{array}{l}16 \\
46 \pm 16 \\
5: 11 \\
164 \pm 8 \\
2 \cdot 24 \pm 0 \cdot 8 \\
0 \cdot 10 \pm 0 \cdot 05 \\
0 \cdot 33 \pm 4 \cdot 2^{*} \\
7 \cdot 6 \pm 2 \cdot 2^{*} \\
58 \pm 20\end{array}$ & $\begin{array}{l}p<0.05 \\
\text { NS } \\
\text { NS } \\
p<0.001 \\
p<0.001 \\
p<0.001 \\
p<0.001 \\
\text { NS }\end{array}$ \\
\hline
\end{tabular}

*Geometric mean and geometric standard deviation. 


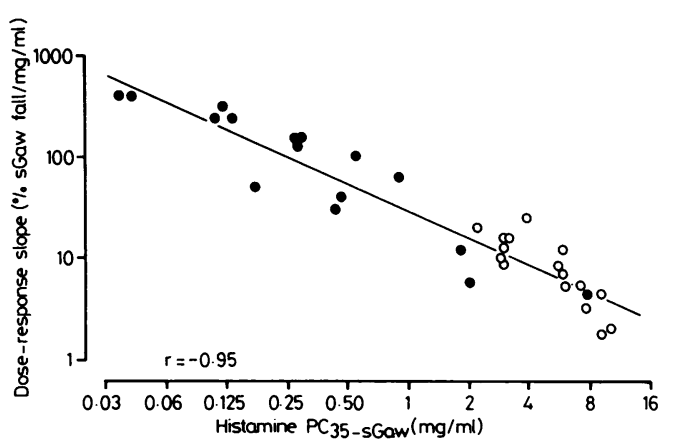

Fig 3 Histamine $\mathrm{PC}_{35-\mathrm{sGaw}}$ versus slope of the histamine dose-response curve, showing a strong negative correlation $(r=-0.95, p \ll 0.001)$. Solid circles represent the 16 asthmatic and open circles the 16 normal subjects.

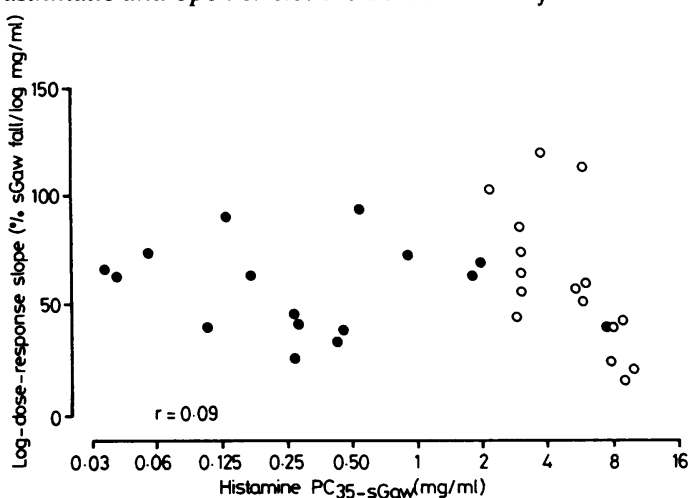

Fig 4 Histamine $\mathrm{PC}_{35-\mathrm{sGaw}}$ versus slope of the histamine log-dose-response curve, with no correlation evident $(r=-0.09, p>0.05)$. Solid circles represent the 16 asthmatic and open circles the 16 normal subjects.

\section{Discussion}

This investigation was carried out to examine the usefulness of measurements of the slope of the histamine dose-response curve, or the so-called reactivity, when applied to a test procedure which has been well standardised to give reproducible values for histamine $\mathrm{PC}_{20}$, the so-called sensitivity. It must be concluded from this study that on the basis of this testing procedure there appears little to be gained from measuring both "reactivity" and "sensitivity" in assessing the bronchial response to inhaled histamine.

The study was not performed to examine in detail the characteristics of the histamine dose-response curve. From this point of view there are several shortcomings in the current methods. For a detailed analysis of the dose-response curve ideally more data points should have been obtained, certainly more than two, for all regressions. Under ideal con- ditions the best procedure would be to continue measurements for the dose-response curve until the maximum or "plateau" response had occurred. This is, of course, not possible in man. Consequently, a poor second choice would be to fix the upper limit of response at a set percentage reduction in $\mathrm{FEV}_{1}$ or sGaw, the theory being that this might approximate a fixed point (that is, a fixed percentage of maximum response) on the total dose-response curve. In the current study a minority of slopes were calculated from only two points-nine of 40 in the $\mathrm{FEV}_{1}$ study and two of 32 in the sGaw study. Although we might reasonably question the accuracy of the slope calculated from only two points, these slopes did in fact fit as well as those determined from three or four points in the regressions shown in figures 1 and 3 . The failure to specify a set upper limit of response in this study is also less than ideal. All subjects in the FEV study had a $20 \%$ or greater fall in FEV and the range of maximum response was $20-40 \%$ (mean $29 \pm 8 \%$ ), whereas all the subjects in the sGaw study had a greater than $30 \%$ reduction in sGaw, with a range of $30-70 \%$ (mean $49 \pm 14 \%$ ). Fixing the upper limit of response would be more important if the dose-response relationship was indeed a "curve" or curvilinear. The fact that the relationship fits the linear model well (the mean $\mathrm{r}^{2}$, if we exclude those slopes calculated from only two points, was 0.98 in the $\mathrm{FEV}_{1}$ study) suggests that the setting of a consistent maximum response for all curves is somewhat less important. If the dose-response relationship is indeed linear, the slope should not be greatly affected by variations in the maximum response. Thus with these provisos it appears feasible to calculate with some accuracy the slope of the histamine dose-response curve from data obtained with our inhalation technique. Theoretically, improved accuracy would result if more concentraions of histamine were used-for example, twice as many-and if the maximum response were set within narrow limits-for example, $30-40 \% \mathrm{FEV}_{1}$ reduction or $40-50 \%$ sGaw reduction. It may not always be possible, however, either because of histamine-induced symptoms or because of failure to obtain a maximum response in the desired range, to achieve this ideal.

A minor finding (for which this study was not designed) was that the histamine dose-response curves appeared to fit the linear model better than logarithmic model. Extrapolation from in vitro muscle studies suggests that dose-response curves for muscle-constricting agents should follow a log dose versus response pattern. ${ }^{15}$ Our findings, however, are consistent with those of Orehek et al, who found that the dose-response curve for carbachol concentration versus sGaw was linear. ${ }^{5}$ In addition, exami- 
nation of the individual dose-response curves for methacholine concentration versus FEV, reported by Felarca and Itkin suggests that these fit a linear better than a logarithmic model. ${ }^{16}$

We found that the slope of the histamine doseresponse curve showed a strong negative correlation both with the $\mathrm{PC}_{20-\mathrm{FEV}}$, and with the $\mathrm{PC}_{35 \text {-sGaw }}(\mathrm{r}=$ -0.98 and -0.95 respectively). This shows that both increasing dose-response slopes and decreasing $\mathrm{PC}_{20}$ or $\mathrm{PC}_{35}$ reflect increasing bronchial responsiveness to inhaled histamine. The very close correlation, especially with $\mathrm{PC}_{20}$, suggests that the measurements may be used interchangeably, and that with knowledge of the $\mathbf{P C}_{20}$ one could accurately predict the slope of the curve. Thus the slope appears to provide little added information. These results are at variance with those of Orehek $e t$ al, who showed no correlation between the slope of the carbachol dose-response curve and the $\mathrm{PC}_{25-\mathrm{sGaw}}$. $^{5}$ That study used a cumulative carbachol dose response curve, ${ }^{5}$ whereas ours used a dose-response curve based on histamine, which has been previously shown to have no cumulative effect. ${ }^{7}$ There are other differences in the design of the studies which might be relevant in explaining the difference. Orehek et al studied a smaller number of subjects with a narrower range of bronchial responses, the range for $\mathrm{PC}_{25 \text {-sGaw }}$ being only 20 -fold. ${ }^{5}$ A second difference is that they produced a greater fall in sGaw in all subjects, attempting to achieve a $75 \%$ reduction in all and reaching at least a $50 \%$ reduction in all. Whether the differences between our results and those of Orehek et al are due to inherent differences between histamine and cholinergic agonists, to differences between cumulative and non-cumulative dose-response curves, or to other technical factors is not clear.

Although the log-dose-response slope was not as accurate a description of the curve as the linear, it did provide a reasonable fit $\left(r^{2}=0.93\right.$ and 0.90$)$. The log-dose-response slope showed only a weak negative correlation with $\mathrm{PC}_{20-\mathrm{FEV}_{1}}$ and no correlation with $\mathbf{P C}_{35-\mathrm{sGaw}}$. The relatively narrow range for the values of this log-dose-response slope, in conjunction with the small or absent trend in the regressions when they were plotted against $\mathrm{PC}_{20}$ and $\mathrm{PC}_{35}$, shows that the log-dose-response slopes are nearly parallel throughout the entire range of bronchial responsiveness, being only slightly steeper at the more responsive end in the $\mathrm{PC}_{20-\mathrm{FEV}_{1}}$ regression (fig 2). This is consistent with the observation of Hargreave et al, who showed parallel log-doseresponse curves for inhaled histamine. ${ }^{17}$ There was no difference in the log-dose-response slope between 16 normal and 16 asthmatic subjects and there was little difference in the clinical features of the subjects with the high slopes and those with the low slopes in the FEV 1 study. The $\mathbf{P C}_{20}$, as expected from the regression, was slightly lower and there was an unexpected and unexplained higher proportion of atopic subjects in those with the high slopes. Thus the log-dose-response slope also fails to add any obvious useful information when it is determined from the results of histamine inhalation tests by this technique.

Using a different approach, Beaupré and Malo have also examined the clinical usefulness of determining the slope of the histamine dose-response curve. ${ }^{18}$ They found that changes in the histamine $\mathrm{PC}_{20-\mathrm{FEV}}$ for individual asthmatic patients correlated with changes in clinical state and that similar information was not available from the slope of the curve.

From this investigation we can draw the following conclusions. Firstly, even though the method fails to fulfil all the theoretical criteria for accurate assessment of the slope of a dose-response curve, it is feasible to obtain a reasonable measurement of the slope of the histamine dose-response curve with our standardised inhalation technique. Secondly, the slope of the dose-response curve, within the range of responses that we measured, appears to fit a linear curve better than a logarithmic curve. Thirdly, the high correlation between the slope and $\mathrm{PC}_{20}$ (or $\mathbf{P C}_{35}$ ) indicates that little information is gained by determining both from the bronchial provocation dose-response curve. Finally, the less significant log-dose-response slope correlated poorly with $\mathrm{PC}_{20}$ and $\mathrm{PC}_{35}$ and also appeared to add little information that was not available from the determination of the $\mathrm{PC}_{20}$ (or $\mathrm{PC}_{35}$ ) alone. We suggest that the easiest and most useful measurement of non-specific bronchial responsiveness to inhaled histamine or a cholinergic agonist is a measurement of so-called sensitivity such as the $\mathrm{PC}_{20-\mathrm{FEV}_{1}}$ or the $\mathrm{PC}_{35-\mathrm{sGaw}}$.

We wish to thank Miss KA Storey, Mrs R Day, and Mr A Campbell for help in preparing the manuscript. The work was supported by a grant (MA7051) from the Medical Research Council of Canada.

\section{References}

' Orehek J, Gayrard P. Les tests de provocation bronchique non-spécifiques dans l'asthme. Bull Europ Physiopath Respir 1976;12:565-98.

${ }^{2}$ Boushey HA, Holtzman MJ, Sheller JR, Nadel JA. Bronchial hyperreactivity. Am Rev Respir Dis 1980;121:389-413.

${ }^{3}$ Cockcroft DW, Killian DN, Mellon JJA, Hargreave FE. Bronchial reactivity to inhaled histamine: a method and clinical survey. Clin Allergy 1977;7:235-43.

${ }^{4}$ Gerrard JW, Cockcroft DW, Mink JT, Cotton DJ, 
Poonawala R, Dosman JA. Increased nonspecific bronchial reactivity in cigarette smokers with normal lung function. Am Rev Respir Dis 1980;122:577-581.

5 Orehek J, Gayrard P, Smith AP, Grimaud C, Charpin J. Airway responses to carbachol in normal and asthmatic subjects: distinction between bronchial sensitivity and reactivity. Am Rev Respir Dis 1977;115:937-43.

- Cockcroft DW, Killian DN, Mellon JJA, Hargreave FE. Protective effect of drugs on histamine-induced asthma. Thorax 1977;32:429-437.

7 Juniper EF, Frith PA, Dunnett C, Cockcroft DW, Hargreave FE. Reproducibility and comparison of responses to inhaled histamine and methacholine. Thorax 1978;33:705-10.

- Ryan G, Dolovich MB, Obminski G, Cockcroft DW, Juniper EF, Hargreave FE, Newhouse MT. Standardization of inhalation provocation tests: influence of nebulizer output, particle size, and method of inhalation. J Allergy Clin Immunol 1981;67:156-161.

9 Ryan G, Dolovich MB, Roberts RS, Frith PA, Juniper EF, Hargreave FE, Newhouse MT. Standardization of inhalation provocation tests: two techniques of aerosol generation and inhalation compared. Am Rev Respir Dis 1981;123:195-9.

${ }^{10}$ American Thoracic Society. Chronic bronchitis, asthma, and pulmonary emphysema-a statement by the committee on diagnostic standards for nontuberculous respiratory disease. Am Rev Respir Dis 1962;85:762-8.

1 Steel RDG, Torrie JH. Principles and procedures of statistics with special reference to the biological sci- ences. New York: McGraw Hill, 1960:161-93.

12 Steel RDG, Torrie JH. Principles and procedures of statistics with special reference to the biological sciences. New York: McGraw Hill, 1960: p62.

${ }^{13}$ Steel RDG, Torrie JH. Principles and procedures of statistics with special reference to the biological sciences. New York: McGraw Hill, 1960: 67.

14 Steel RDG, Torrie JH. Principles and procedures of statistics with special reference to the biological sciences. New York: McGraw Hill, 1960: 352.

15 Stephens NL, Mitchell RW, Antonissen LA, Kromer U, Hanks B, Kroeger EA, Kepron W. Airway smooth muscles: physical properties and metabolism. In: Hargreave FE. Airway reactivity-mechanisms and clinical relevance. Mississauga; Astra Pharmaceuticals Canada Ltd, 1980: 110-31.

${ }^{16}$ Felarca AB, Itkin IH. Studies with quantitativeinhalation challenge technique. 1 Curve of dose response to acetyl-beta-methylcholine in patients with asthma of known and unknown origin, hay fever subjects and nonatopic volunteers. $J$ Allergy 1966;37:223-35.

${ }^{17}$ Hargreave FE, Juniper EF, Ryan G, et al. Clinical significance of nonspecific airway hyperreactivity. In: Hargreave FE. Airway reactivity: mechanisms and clinical relevance. Mississauga: Astra Pharmaceuticals Canada Ltd, 1980:216-21.

18 Beaupré A, Malo JL. Histamine dose-response curves in asthmatics: relevance of the distinction between $\mathrm{PC}_{20}$ and reactivity in characterizing clinical state. $J$ Allergy Clin Immunol 1981;67, suppl 11: (abstract). 